\title{
Acute metabolic responses to a high-carbohydrate meal in outpatients with type 2 diabetes treated with a low-carbohydrate diet: a crossover meal tolerance study

\author{
Hajime Haimoto*1, Tae Sasakabe ${ }^{2}$, Hiroyuki Umegaki ${ }^{3}$ and Kenji Wakai ${ }^{4}$
}

\begin{abstract}
Address: ${ }^{1}$ Department of Internal Medicine, Haimoto Clinic, 1-80 Yayoi, Kasugai, Aichi 486-0838, Japan, ${ }^{2}$ Department of Clinical Nutrition, Haimoto Clinic, 1-80 Yayoi, Kasugai, Aichi 486-0838, Japan, ${ }^{3}$ Department of Geriatrics, Nagoya University Graduate School of Medicine, 65 Tsurumai, Showa, Nagoya, Aichi 466-8550, Japan and ${ }^{4}$ Department of Preventive Medicine/Biostatistics and Medical Decision Making, Nagoya University Graduate School of Medicine, 65 Tsurumai, Showa, Nagoya, Aichi 466-8550, Japan

Email: Hajime Haimoto* - haimoto@gol.com; Tae Sasakabe - haiclipar-mail78@gol.com; Hiroyuki Umegaki - umegaki@med.nagoya-u.ac.jp; Kenji Wakai - wakai@med.nagoya-u.ac.jp

* Corresponding author
\end{abstract}

Published: 29 December 2009

Nutrition \& Metabolism 2009, 6:52 doi:10.1 186/1743-7075-6-52
Received: 14 August 2009

Accepted: 29 December 2009

This article is available from: http://www.nutritionandmetabolism.com/content/6/1/52

(C) 2009 Haimoto et al; licensee BioMed Central Ltd.

This is an Open Access article distributed under the terms of the Creative Commons Attribution License (http://creativecommons.org/licenses/by/2.0), which permits unrestricted use, distribution, and reproduction in any medium, provided the original work is properly cited.

\begin{abstract}
Background: A low-carbohydrate diet (LCD) achieves good glycemic control in type 2 diabetes (T2DM) compared with a high-carbohydrate diet. With respect to energy metabolism, acute metabolic responses to high-carbohydrate meals (HCMs) have not been determined in LCD patients with T2DM.

Subjects and methods: We enrolled $3 \mathrm{I}$ subjects with T2DM (mean age: 62 yrs, mean hemoglobin AIc level: 6.9\%), of whom 13 were on a strict LCD ( $26 \%$ carbohydrate diet), and 18 a moderate one ( $44 \%$ carbohydrate diet). Two isocaloric meals were administered to all subjects in a randomized crossover design. The carbohydrate:protein:fat ratios of HCMs and low-carbohydrate meals (LCMs) were 59:20:2I and 7:20:73, respectively. Serum $\beta$-hydroxybutyrate, acetoacetate, free fatty acids (FFAs), triglyceride and insulin, and plasma glucose concentrations were measured for 120 minutes after the intake of each meal.
\end{abstract}

Results: HCMs rapidly decreased postprandial $\beta$-hydroxybutyrate, acetoacetate and FFA concentrations within 2 hours in all patients in combination with rapid increases in serum insulin and plasma glucose, while LCMs increased or did not change $\beta$-hydroxybutyrate, acetoacetate and FFAs $(P<0.00 \mathrm{I}$ for all). HCMs did not change postprandial triglyceride concentrations over 2 hours, while LCMs gradually increased them $(P<0.00 \mathrm{I})$.

HCMs sharply and rapidly decreased postprandial $\beta$-hydroxybutyrate and acetoacetate concentrations in strict LCD subjects over 2 hours, but only slightly decreased them in moderate LCD subjects $(P<0.00$ I, difference between strict and moderate LCD subjects). The parameter $\Delta$ ketone bodies (level at I 20 minutes - level at baseline) was significantly correlated with the insulinogenic index (Spearman's $r=0.503$ for $\beta$-hydroxybutyrate and 0.509 for acetoacetate), but not with total insulin secretory capacity. Moreover, HCMs slightly decreased postprandial triglyceride levels in strict LCD subjects but somewhat increased them in the moderate LCD subjects $(P=0.002)$. The parameter $\Delta$ triglyceride was significantly correlated with background dietary \%carbohydrate (Spearman's $r=0.484$ ).

Conclusion: HCMs rapidly decreased postprandial ketone body concentrations in T2DM patients treated with a LCD. The decreases were more remarkable in strict than in moderate LCD subjects. HCMs slightly decreased postprandial triglyceride levels in strict LCD subjects. The parameter $\Delta$ ketone bodies was significantly correlated with the insulinogenic index, as was $\Delta$ triglyceride with background dietary \%carbohydrate. 


\section{Introduction}

Low-carbohydrate diets (LCDs) are known to be more effective than high-carbohydrate diets (HCDs) in improving glycemic control in type 2 diabetes mellitus (T2DM) $[1,2]$. Our carbohydrate-reduced diet (CARD) also showed efficacy and safety over 2 years in mild T2DM [3], with an efficacy comparable to that provided by insulin therapy in severe T2DM [4]. An important problem with LCDs, however, is the high attrition rate $[2,3,5]$. Even patients who strictly conform to LCDs sometimes crave a high-carbohydrate meal (HCM), which often triggers the patients to drop out from the LCDs.

Although a key adaptation of LCDs is the production and utilization of ketone bodies [6,7], the potential of such bodies for uses other than as fuels remains unclear [7]. Even moderate LCDs (30-45\% carbohydrate diets) are highly effective for T2DM and dyslipidemia $[2,3,8]$. Thus, patients on a less-strict LCD sometimes eat HCMs because they are not required to strictly limit carbohydrates. Nevertheless, little is known about the acute metabolic changes resulting from the change in carbohydrate conditions in such patients.

In the present study, our subjects, T2DM outpatients on CARD, underwent crossover meal tolerance tests (HCM vs. a low-carbohydrate meal, LCM) to compare the acute effects of HCMs and LCMs on postprandial serum ketone bodies, free fatty acids (FFAs) and triglycerides. We also compared acute responses between subjects on moderate (non-ketogenic) and strict (ketogenic) CARD. Furthermore, for HCMs, we examined the correlation of post- prandial changes in serum ketone bodies, FFAs and triglycerides with an increase in postprandial plasma glucose, insulin secretory capacity and background dietary \%carbohydrate.

\section{Subjects and methods}

Thirty-one volunteer T2DM outpatients from the Haimoto Clinic participated in the study (Table 1). All patients were Japanese. Patients with severe diabetes complications were excluded. The participants achieved relatively good glycemic control (mean hemoglobin A1c (HbA1c) level: $6.9 \pm 0.4 \%$ ) by implementing CARD for a mean duration of 22 months. They received no insulin, sulfonylurea or nateglinide treatment, and their mean HbA1c level before CARD was $8.9 \pm 2.0 \%$. Based on their initial HbA1c levels, 18 were assigned moderate CARD and 13 strict CARD $[3,4]$. Nine subjects took glucose-lowering medication (miglitol, metformin and pioglitazone).

The HCMs and LCMs were prepared at the Haimoto Clinic by an experienced dietitian. The total energy of the two meals was identical, while the macronutrient composition was contrastive (Table 2). The target HCM macronutrient composition followed the guidelines of the Japan Diabetes Society [9]. The background dietary intake of the subjects was assessed using 3-day food records.

All 31 participants underwent two-meal tolerance tests at intervals of 7-14 days. They were randomly assigned to two groups: 15 subjects took HCMs and LCMs in the first and second tests, respectively, while 16 subjects received LCMs and HCMs in the first and second sessions, respec-

Table I: Background characteristics of participants

\begin{tabular}{|c|c|c|c|c|}
\hline & $\begin{array}{l}\text { All subjects } \\
(n=31)\end{array}$ & $\begin{array}{c}\text { Moderate CARD subjects } \\
(n=18)\end{array}$ & $\begin{array}{l}\text { Strict CARD subjects } \\
(n=13)\end{array}$ & $P^{*}$ \\
\hline Male/Female & $17 / 14$ & $9 / 9$ & $8 / 5$ & \\
\hline Age (yrs) & $62 \pm 7$ & $62 \pm 6$ & $62 \pm 7$ & 0.98 \\
\hline Body mass index & $23.2 \pm 3.4$ & $22.9 \pm 3.3$ & $23.6 \pm 3.5$ & 0.56 \\
\hline Duration of diabetes (months) & $89 \pm 55$ & $80 \pm 40$ & $101 \pm 68$ & 0.34 \\
\hline Duration of CARD (months) & $22 \pm 16$ & $27 \pm 16$ & $16 \pm 13$ & 0.040 \\
\hline $\mathrm{HbAlc}(\%)$ & $6.9 \pm 0.4$ & $6.9 \pm 0.4$ & $6.8 \pm 0.4$ & 0.37 \\
\hline HbAIc before CARD (\%) & $8.9 \pm 2.0$ & $8.3 \pm 1.4$ & $9.6 \pm 2.4$ & 0.099 \\
\hline Serum LDL cholesterol (mg/dl) & || $7 \pm 2 \mid$ & $110 \pm 17$ & $126 \pm 22$ & 0.040 \\
\hline Serum HDL cholesterol (mg/dl) & $62 \pm 12$ & $61 \pm 13$ & $64 \pm 10$ & 0.57 \\
\hline Serum triglyceride (mg/dl) & $94 \pm 42$ & $98 \pm 37$ & $111 \pm 58$ & 0.47 \\
\hline \multicolumn{5}{|l|}{ Dietary intake } \\
\hline Total energy (kcal/day) & $1808 \pm 495$ & $1713 \pm 423$ & $1990 \pm 57 \mid$ & 0.15 \\
\hline Carbohydrate (g/day) & $158 \pm 48$ & $179 \pm 35$ & $127 \pm 46$ & 0.002 \\
\hline Carbohydrate (\% energy) & $36 \pm 10$ & $42 \pm 4$ & $26 \pm 7$ & $<0.001$ \\
\hline Fat (g/day) & $75 \pm 21$ & $67 \pm 17$ & $92 \pm 26$ & 0.006 \\
\hline Fat (\% energy) & $38 \pm 9$ & $35 \pm 5$ & $44 \pm 12$ & 0.033 \\
\hline Protein (g/day) & $81 \pm 21$ & $78 \pm 22$ & $90 \pm 21$ & 0.13 \\
\hline Protein (\% energy) & $18 \pm 3$ & $18 \pm 3$ & $19 \pm 4$ & 0.71 \\
\hline
\end{tabular}

Plus-minus values are means $\pm \mathrm{SD}$. CARD: Carbohydrate-reduced diet, HbAlc: Hemoglobin Alc.

*: $P$ for the difference between the moderate and strict CARD subjects. 
Table 2: Composition of test meals

\begin{tabular}{|c|c|c|}
\hline & Low-carbohydrate meal & High-carbohydrate meal \\
\hline Total energy (kcal) & 500 & 500 \\
\hline Carbohydrate (\% energy) & 7 & 59 \\
\hline Fat (\% energy) & 73 & 21 \\
\hline Protein (\% energy) & 20 & 20 \\
\hline Carbohydrate $(\mathrm{g})$ & 9 & 73 \\
\hline Fat $(g)$ & 42 & 12 \\
\hline Saturated fatty acids (g) & 12 & 3 \\
\hline Monounsaturated fatty acids (g) & 17 & 3 \\
\hline Polyunsaturated fatty acids (g) & 9 & 3 \\
\hline Protein $(\mathrm{g})$ & 23 & 23 \\
\hline Menu & $\begin{array}{c}\text { Pork back rib char boiled }(86 \mathrm{~g}), \\
\text { tuna salad }(59 \mathrm{~g}) \\
\text { mixed beans }(20 \mathrm{~g}) \\
\text { lettuce }(10 \mathrm{~g}) \\
\text { boiled egg }(50 \mathrm{~g}) \\
\text { tomato }(10 \mathrm{~g})\end{array}$ & $\begin{array}{c}\text { Rice cake }(140 \mathrm{~g}), \\
\text { mackerel boiled Japanese bean taste (36 g), } \\
\text { beans and seaweeds }(33 \mathrm{~g}), \\
\text { cooked egg }(50 \mathrm{~g}), \\
\text { lettuce }(10 \mathrm{~g}), \\
\text { tofu (soybean curd) soup }(33 \mathrm{~g}), \\
\text { tomato }(10 \mathrm{~g}), \\
\text { apple }(20 \mathrm{~g})\end{array}$ \\
\hline
\end{tabular}

tively. Each meal test was conducted after a 12-hour overnight fast. The subjects were asked to continue their CARD and physical activity during the study period. After blood sampling at baseline ( 0 minutes), the subjects were asked to consume the test meal in 10 minutes, and blood was collected after 30, 60 and 120 minutes. All antidiabetic and lipid-lowering drugs were stopped for 24 hours before each tolerance test.

Plasma glucose concentration was determined by enzymatic methods (Shino-Test Co. Kanagawa, Japan). Serum immunoreactive insulin was measured using the standard double antibody radioimmunoassay method (Fujirebio Inc. Tokyo, Japan). Enzymatic methods were used to measure serum total cholesterol (Sysmex Co., Hyogo, Japan), triglycerides (Daiichi Pure Chemicals Co., Tokyo, Japan), free fatty acids (Eiken Chemicals Co., Tokyo, Japan), $\beta$-hydroxybutyrate and acetoacetate (Kainos Laboratories Inc., Tokyo, Japan). Direct methods were used to assay serum LDL-cholesterol and HDL-cholesterol (Daiichi Pure Chemicals Co., Tokyo, Japan). HbA1c level was measured by high-performance liquid chromatography (Arkley Co., Kyoto, Japan).

The study protocol was approved by the Ethical Committee of the Nagoya Tokusyukai General Hospital, and all participants provided written informed consent.

\section{Statistical analysis}

Repeated-measures analysis of variance (ANOVA) was used to examine differences in the time course of each substance. The baseline levels of each biomarker were compared between the two meals by paired $t$-test, and those between the moderate and strict CARD groups were compared by unpaired $t$-test.
With respect to the responses to HCMs, we computed Spearman's correlation coefficients to examine the correlation of the changes in serum postprandial ketone body ( $\Delta \beta$-hydroxybutyrate and $\Delta$ acetoacetate), FFA ( $\Delta$ FFAs) and triglyceride ( $\Delta$ triglyceride) levels with an increase in plasma glucose levels, insulin secretory capacity and background dietary \%carbohydrate as assessed by 3-day food records. The parameters $\Delta$ ketone bodies, $\Delta$ FFAs and $\Delta$ triglyceride were defined as the level at 120 minutes minus the level at baseline. The incremental plasma glucose $(\Delta$ glucose) and serum insulin ( $\Delta$ insulin) were calculated as the difference between the baseline and the peak. The trapezoidal rule was used to calculate the incremental area under the curve for glucose (AUC-glucose) and insulin (AUC-insulin). The HOMA-R and insulinogenic index were computed as follows: [fasting plasma glucose $(\mathrm{mg} /$ $\mathrm{dl})] \times[$ fasting serum insulin $(\mu \mathrm{IU} / \mathrm{ml})] / 405$ and $([$ serum insulin at 30 minutes] - [serum insulin at baseline])/ ([plasma glucose at 30 minutes] - [plasma glucose at baseline]), respectively (9).

All values were expressed as means \pm SD. $P<0.05$ was considered statistically significant.

\section{Results}

\section{Comparison between HCM and LCM}

The baseline concentrations of all substances were not significantly different between the HCM and LCM tolerance tests (Figures 1, 2 and 3). LCMs increased postprandial glucose and insulin concentrations only slightly $(139 \pm 21$ $\mathrm{mg} / \mathrm{dl}$ and $6.4 \pm 4.6 \mu \mathrm{IU} / \mathrm{ml}$ at baseline, $143 \pm 23 \mathrm{mg} / \mathrm{dl}$ and $10.3 \pm 6.4 \mu \mathrm{IU} / \mathrm{ml}$ after $30 \mathrm{~min}, 144 \pm 23 \mathrm{mg} / \mathrm{dl}$ and $11.6 \pm 7.4 \mu \mathrm{IU} / \mathrm{ml}$ after $60 \mathrm{~min}$, and $142 \pm 22 \mathrm{mg} / \mathrm{dl}$ and $11.4 \pm 7.4 \mu \mathrm{IU} / \mathrm{ml}$ after $120 \mathrm{~min}$, respectively), while HCMs caused them to increase rapidly $(134 \pm 20 \mathrm{mg} / \mathrm{dl}$ 

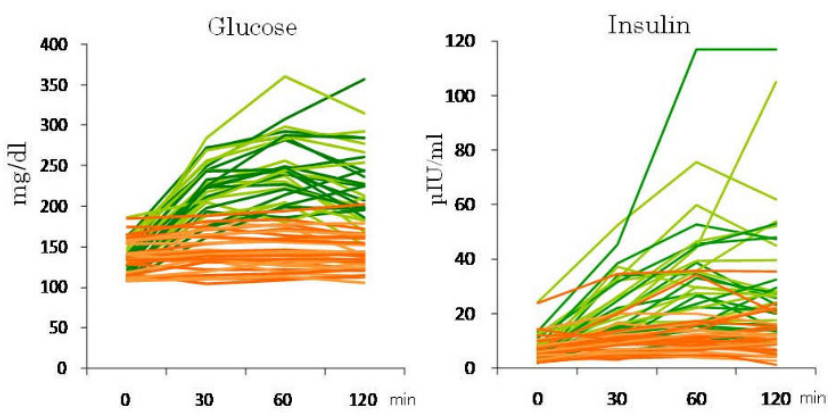

Figure I

Postprandial glucose and insulin concentrations under HCM (green) and LCM (orange) in all individual subjects. HCMs caused postprandial glucose and insulin concentrations to increase rapidly, while LCMs increased them only slightly $(P<0.001$ for the difference between the two meals for both glucose and insulin).

and $6.6 \pm 4.7 \mu \mathrm{IU} / \mathrm{ml}$ at baseline, $223 \pm 33 \mathrm{mg} / \mathrm{dl}$ and 21.7 $\pm 1.5 \mu \mathrm{IU} / \mathrm{ml}$ after $30 \mathrm{~min}, 245 \pm 42 \mathrm{mg} / \mathrm{dl}$ and $33.6 \pm$ $21.8 \mu \mathrm{IU} / \mathrm{ml}$ after $60 \mathrm{~min}$, and $227 \pm 49 \mathrm{mg} / \mathrm{dl}$ and $34.6 \pm$ $24.9 \mu \mathrm{IU} / \mathrm{ml}$ after $120 \mathrm{~min}$, respectively) $(P<0.001$ for the difference between the two meals for both glucose and insulin; Figure 1). HCMs rapidly decreased postprandial $\beta$-hydroxybutyrate, acetoacetate and FFA concentrations, while LCMs increased or did not change them $(P<0.001$ for the difference between the two meals for all substances; Figure 2). LCMs increased postprandial triglyceride concentrations, while HCMs induced little change $(P$ $<0.001$ for the difference between the two meals; Figure 3).

\section{Background characteristics of the moderate and strict CARD groups}

Background total energy intake was not significantly different between the two groups (Table 1). The daily average intakes of carbohydrates and fat, however, differed greatly, with the strict and moderate CARD groups achieving $26 \%$ and $42 \%$ carbohydrate diets, respectively. The baseline concentrations of serum $\beta$-hydroxybutyrate and acetoacetate were significantly higher in the strict CARD group before HCM and LCM $(P<0.02$ for all; Table 3$)$. Those of other substances were not significantly different between the two groups, with the exception that the strict CARD group showed a higher serum FFA level before the LCM test $(P=0.04)$.

\section{Differences between the moderate and strict CARDs in two-meal tests}

No significant differences were found in the time courses of the postprandial glucose or insulin levels between the
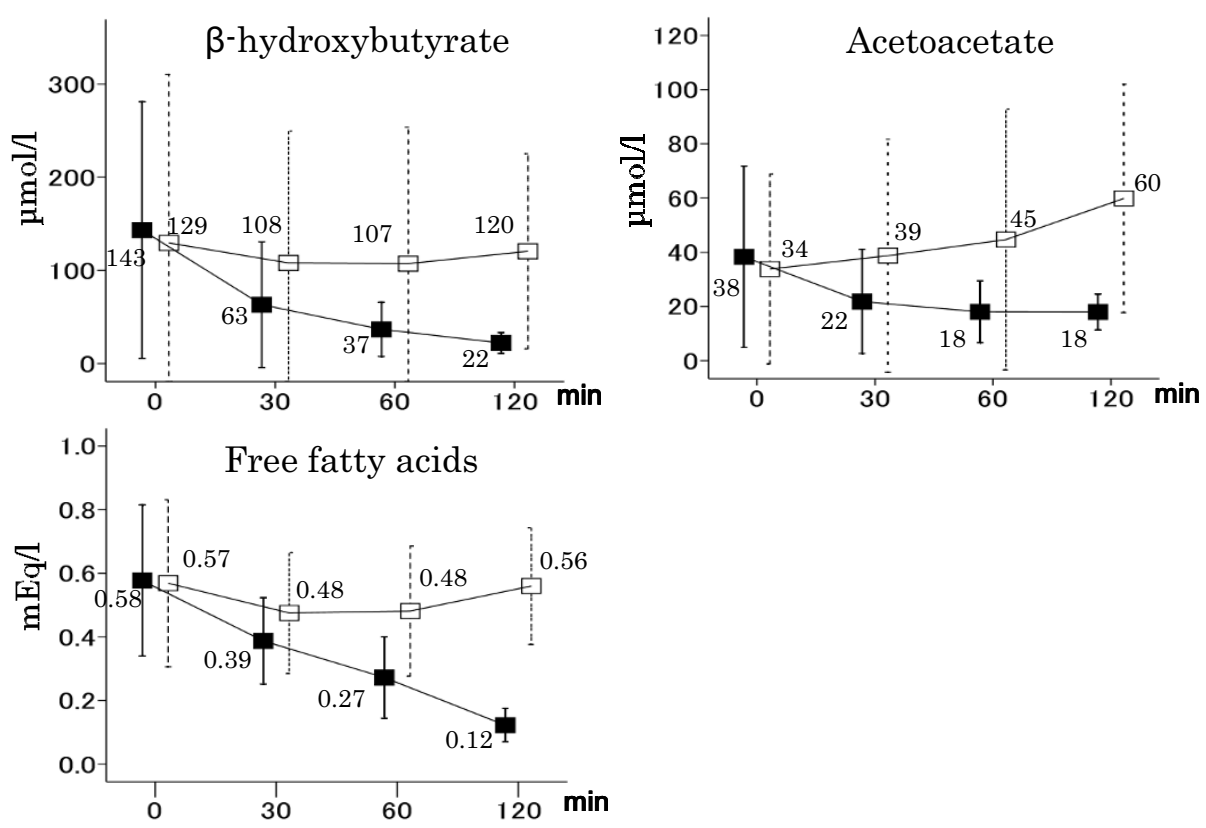

\section{Figure 2}

Postprandial -hydroxybutyrate, acetoacetate and FFA concentrations under HCM and LCM in all subjects. Vertical lines show means \pm SD. HCMs (black square) rapidly decreased postprandial $\beta$-hydroxybutyrate, acetoacetate and FFA concentrations, while LCMs (white square) increased or did not change them $(P<0.00$ I for the difference between the two meals for $\beta$-hydroxybutyrate, acetoacetate and FFAs). 


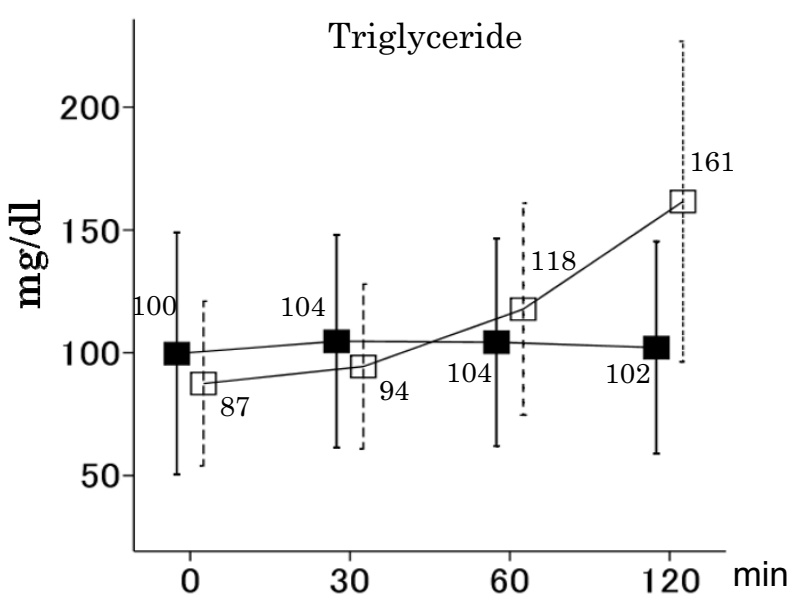

Figure 3

Postprandial triglyceride concentrations under HCM and LCM in all subjects. Vertical lines show means \pm SD. LCMs (white square) increased postprandial triglyceride concentrations, while HCMs (black square) induced little change $(P<0.00$ I for the difference between the two meals).

moderate and strict CARD groups after the intake of HCM and $\operatorname{LCM}(P>0.05$ for all; Table 3$)$.

HCMs sharply decreased the postprandial serum $\beta$ hydroxybutyrate and acetoacetate concentrations in the strict CARD group, and only slightly decreased them in the moderate group (Table 3, Figures 4 and 5). The time courses were significantly different between the two groups $(P=0.001$ for both). LCMs slightly decreased the postprandial $\beta$-hydroxybutyrate levels in the strict CARD group, and increased them somewhat in the moderate group $(P=0.012$ for the difference in the time course; Table 3 and Figure 4). LCMs gradually increased the postprandial acetoacetate concentrations in both groups $(P=$ 0.95 for the difference in the time course; Table 3 and Figure 5). The time course of postprandial FFA concentrations was not significantly different between the two groups for both meals.

HCMs slightly decreased postprandial triglyceride levels in the strict CARD group over 120 minutes, and slightly increased them in the moderate group (Table 3 and Figure $6)$. The time courses of the two groups were significantly different $(P=0.014)$. LCMs increased the levels linearly over 120 minutes in both groups $(P=0.89$ for the difference in the time course).

Correlation of changes in postprandial serum levels of ketone bodies, FFAs and triglycerides with insulin secretory capacity, background dietary \%carbohydrate and increases in glucose levels after intake of HCM

Both $\Delta \beta$-hydroxybutyrate and $\Delta$ acetoacetate were strongly and positively correlated with the insulinogenic index (Table 4 and Figure 7), moderately and inversely with $\Delta$ glucose and AUC-glucose and moderately and positively with background dietary \%carbohydrate (Table 4 and Figure 8 ), while they were not significantly correlated with

Table 3: Differences in the time course for postprandial plasma glucose and serum insulin, ketone body, FFA and triglyceride levels between the moderate and strict CARD subjects after intake of the two meals

\begin{tabular}{|c|c|c|c|c|c|c|c|c|c|}
\hline & \multicolumn{9}{|c|}{ High-carbohydrate meal } \\
\hline & \multicolumn{4}{|c|}{ Moderate CARD subjects $(n=18)$} & \multicolumn{4}{|c|}{ Strict CARD subjects $(n=13)$} & $\mathbf{P} *$ \\
\hline & Baseline & $30 \mathrm{~min}$ & $60 \mathrm{~min}$ & $120 \mathrm{~min}$ & Baseline & $30 \mathrm{~min}$ & $60 \mathrm{~min}$ & $120 \mathrm{~min}$ & \\
\hline Glucose (mg/dl) & $129 \pm 18$ & $214 \pm 34$ & $229 \pm 35$ & $213 \pm 39$ & $142 \pm 20$ & $223 \pm 33$ & $245 \pm 42$ & $227 \pm 48$ & 0.13 \\
\hline Insulin $(\mu \mathrm{lU} / \mathrm{ml})$ & $6.2 \pm 4.6$ & $24.2 \pm 13.4$ & $36.3 \pm 26.4$ & $37.3 \pm 30.8$ & $6.2 \pm 2.2$ & $18.2 \pm 7.3$ & $29.9 \pm 13.2$ & $30.8 \pm 13.6$ & 0.51 \\
\hline $\mathrm{BHB}(\mu \mathrm{mol} / \mathrm{l})$ & $80 \pm 55$ & $33 \pm 14$ & $25 \pm 7$ & $17 \pm 4$ & $231 \pm 169$ & $104 \pm 89$ & $53 \pm 39$ & $29 \pm 14$ & 0.001 \\
\hline Acetoacetate $(\mu \mathrm{mol} / \mathrm{l})$ & $22.5 \pm 13.8$ & $13.8 \pm 5.3$ & $13.5 \pm 5.6$ & $15.4 \pm 4.1$ & $60.2 \pm 40.5$ & $32.9 \pm 25.4$ & $24.3 \pm 14.3$ & $21.5 \pm 7.9$ & 0.001 \\
\hline FFAs (mEq/l) & $0.50 \pm 0.15$ & $0.35 \pm 0.13$ & $0.24 \pm 0.10$ & $0.11 \pm 0.04$ & $0.69 \pm 0.29$ & $0.44 \pm 0.14$ & $0.31 \pm 0.16$ & $0.14 \pm 0.07$ & 0.06 \\
\hline \multirow[t]{4}{*}{ Triglyceride (mg/dl) } & $94 \pm 41$ & $|0| \pm 4 \mid$ & $103 \pm 40$ & $107 \pm 43$ & $108 \pm 59$ & $109 \pm 48$ & $106 \pm 47$ & $95 \pm 44$ & 0.014 \\
\hline & \multicolumn{9}{|c|}{ Low-carbohydrate meal } \\
\hline & \multicolumn{4}{|c|}{ Moderate CARD subjects $(n=18)$} & \multicolumn{4}{|c|}{ Strict CARD subjects $(n=13)$} & $\mathbf{P}^{*}$ \\
\hline & Baseline & $30 \mathrm{~min}$ & $60 \mathrm{~min}$ & $120 \mathrm{~min}$ & Baseline & $30 \mathrm{~min}$ & $60 \mathrm{~min}$ & $120 \mathrm{~min}$ & \\
\hline Glucose (mg/dl) & $135 \pm 23$ & $137 \pm 25$ & $139 \pm 25$ & $137 \pm 25$ & $144 \pm 19$ & $15 \mid \pm 16$ & $151 \pm 19$ & $149 \pm 16$ & 0.35 \\
\hline Insulin $(\mu \mathrm{lU} / \mathrm{ml})$ & $7.1 \pm 5.7$ & $10.9 \pm 7.8$ & $12.7 \pm 9.3$ & $11.7 \pm 8.8$ & $5.5 \pm 2.4$ & $9.6 \pm 3.3$ & $10.1 \pm 3.1$ & $10.9 \pm 5.2$ & 0.67 \\
\hline $\mathrm{BHB}(\mu \mathrm{mol} / \mathrm{l})$ & $56 \pm 30$ & $51 \pm 19$ & $59 \pm 23$ & $78 \pm 32$ & $232 \pm 247$ & $187 \pm 195$ & $174 \pm 211$ & $179 \pm 139$ & 0.012 \\
\hline Acetoacetate $(\mu \mathrm{mol} / \mathrm{l})$ & $17.4 \pm 9.1$ & $20.6 \pm 8.0$ & $27.1 \pm 11.0$ & $42.1 \pm 22.0$ & $56.5 \pm 44.6$ & $63.9 \pm 57.9$ & $69.0 \pm 67.1$ & $84.4 \pm 51.2$ & 0.95 \\
\hline FFAs (mEq/l) & $0.52 \pm 0.21$ & $0.46 \pm 0.22$ & $0.46 \pm 0.22$ & $0.54 \pm 0.21$ & $0.63 \pm 0.32$ & $0.50 \pm 0.15$ & $0.52 \pm 0.19$ & $0.59 \pm 0.14$ & 0.53 \\
\hline Triglyceride (mg/dl) & $95 \pm 35$ & $103 \pm 36$ & $125 \pm 44$ & $169 \pm 62$ & $77 \pm 30$ & $83 \pm 27$ & $108 \pm 42$ & $|52 \pm 7|$ & 0.89 \\
\hline
\end{tabular}

Values are means \pm SD. CARD: carbohydrate-reduced diet, BHB: $\beta$-hydroxybutyrate, FFAs: free fatty acids.

*: $P$ for the difference in the time course between the moderate and strict CARD subjects. 

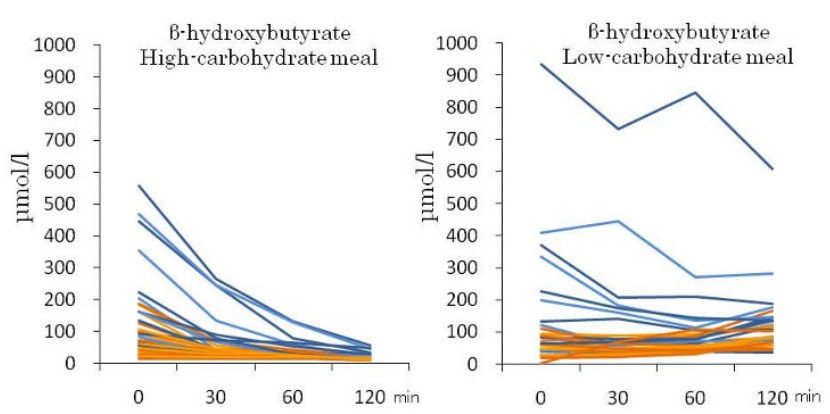

Figure 4

Individual changes in postprandial -hydroxybutyrate levels in the moderate (orange) and strict (blue) CARD subjects after the intake of HCM and LCM.

fasting plasma glucose, fasting serum insulin, $\Delta$ insulin, AUC-insulin and HOMA-R. Namely, postprandial serum ketone body levels decreased more in subjects with lower insulinogenic indices. The results for $\Delta$ FFAs were similar to those for $\Delta$ ketone bodies, but the correlation was somewhat weaker.

Background dietary \%carbohydrate was strongly and positively correlated with $\Delta$ triglyceride and was moderately correlated with $\Delta \beta$-hydroxybutyrate and $\Delta$ acetoacetate. The parameter $\Delta$ triglyceride was not significantly correlated with any variables other than background dietary \%carbohydrate (Table 4 and Figure 8 ). This means that postprandial serum triglycerides decreased more in subjects with lower background dietary \%carbohydrate. Excluding the two subjects with a greatest decrease of serum triglycerides did not materially alter the association between $\Delta$ triglyceride and dietary \%carbohydrate (Spearman's $r=0.487$ [P $=0.007])$.

In terms of the baseline levels of ketone bodies, the insulinogenic index was significantly and inversely correlated
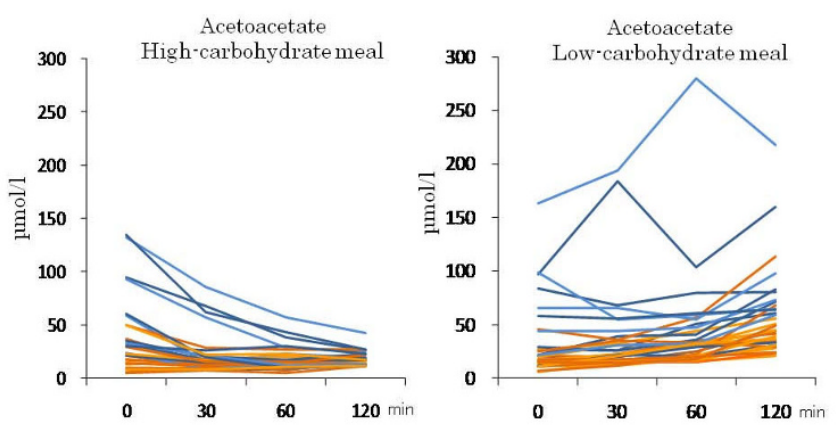

Figure 5

Individual changes in postprandial acetoacetate levels in the moderate (orange) and strict (blue) CARD subjects after the intake of HCM and LCM.
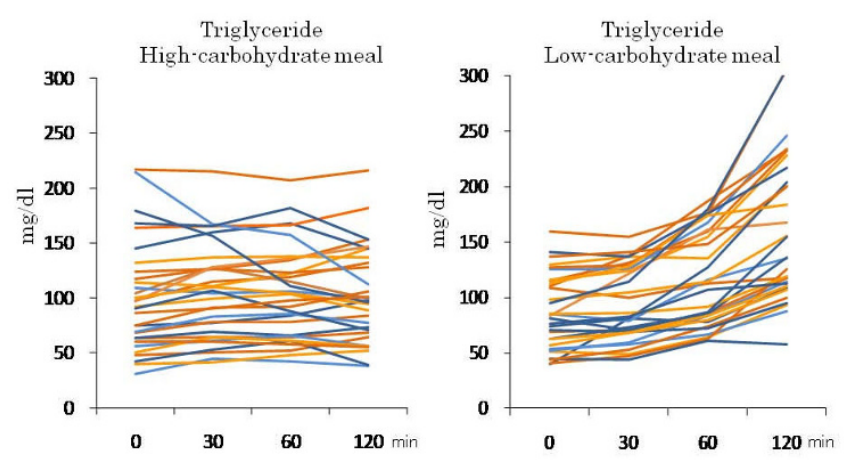

Figure 6

Individual changes in postprandial triglyceride levels in the moderate (orange) and strict (blue) CARD subjects after the intake of HCM and LCM.

with baseline $\beta$-hydroxybutyrate and acetoacetate levels (Spearman's $r=-0.523[P=0.003]$ and $-0.513[P=0.003]$, respectively), as was dietary \%carbohydrate (Spearman's $\mathrm{r}$ $=-0.421[P=0.018]$ and $-0.443[P=0.013]$, respectively).

\section{Discussion}

The limitations of the present study are its very short term and the large SD in serum ketone body levels before the meal tests. Large between-person variations in fasting serum $\beta$-hydroxybutyrate levels have been previously reported in outpatients after long-term LCD treatment $[10,11]$. Another limitation is that the use of glucose and lipid-lowering drugs may have affected the results.

Nevertheless, the present study demonstrated that HCMs including 59\% carbohydrates rapidly decreased postprandial serum ketone body and FFA concentrations within 2 hours in T2DM outpatients on CARD. The decrease can be explained in terms of the metabolic changes of ketone bodies and FFAs to glucose to be used as fuel [12], which is well-known to be largely determined by insulin secretion after the intake of large amounts of carbohydrates $[12,13]$. However, our study clarified that the decrease in serum ketone body levels was much more rapid than expected from starvation conditions [12,14] and was more remarkable in strict (ketogenic) CARD subjects than in moderate (non-ketogenic) CARD subjects. Carbohydrate or glucose administration to fasting normals causes serum ketone body levels to decrease in a few days $[12,14]$. Under low-carbohydrate conditions, unlike under starvation conditions, a sufficient intake of protein and fat is likely to be involved in the rapid decrease of serum ketone body levels.

The present study also demonstrated that the insulinogenic index was strongly and positively correlated with $\Delta$ ketone bodies while concomitantly showing a strong and inverse correlation with baseline ketone body levels, 
Table 4: Correlation of changes in serum ketone bodies, FFAs and triglycerides with insulin response capacity, background dietary \%carbohydrate and increases in plasma glucose after intake of the high-carbohydrate meal

\begin{tabular}{lcccc}
\hline & -hydroxybutyrate & acetoacetate & FFAs & triglyceride \\
\hline Fasting plasma glucose & $-0.261(0.156)$ & $-0.208(0.26)$ & $-0.208(0.26)$ & $0.001(0.10)$ \\
$\Delta$ glucose & $-0.472(0.007)$ & $-0.442(0.012)$ & $-0.302(0.10)$ & $-0.250(0.18)$ \\
AUC-glucose & $-0.450(0.011)$ & $-0.407(0.023)$ & $-0.358(0.048)$ & $-0.149(0.42)$ \\
Fasting serum insulin & $0.279(0.13)$ & $0.145(0.44)$ & $-0.114(0.54)$ & $-0.146(0.42)$ \\
Ainsulin & $0.328(0.072)$ & $0.268(0.15)$ & $0.012(0.95)$ & $-0.097(0.60)$ \\
AUC-insulin & $0.346(0.057)$ & $0.265(0.15)$ & $-0.007(0.97)$ & $-0.165(0.38)$ \\
Insulinogenic index & $0.503(0.004)$ & $0.509(0.003)$ & $0.359(0.047)$ & $0.048(0.80)$ \\
HOMA-R & $0.195(0.292)$ & $-0.129(0.488)$ & $0.035(0.85)$ & $-0.238(0.20)$ \\
\%Carbohydrate & $0.380(0.035)$ & $0.372(0.040)$ & $0.268(0.145)$ & $0.484(0.006)$ \\
\hline
\end{tabular}

Values indicate Spearman's $r$ with $P$ values in parentheses. FFAs: free fatty acids, AUC: area under curve. $\Delta$ glucose and $\Delta$ insulin: level at the peak - level at baseline.

$\Delta \beta$-hydroxybutyrate, $\Delta$ acetoacetate, $\Delta$ free fatty acids ( $\Delta$ FFAs) and $\Delta$ triglyceride: level at 120 minutes - level at baseline.

but total insulin secretory capacity (AUC-insulin) was not significantly correlated with $\Delta$ ketone bodies. A possible interpretation of these findings is that under low-carbohydrate conditions, a lower insulinogenic index is probably a factor in maintaining a high level of baseline ketone bodies independent of dietary \%carbohydrate; then, the initial secretion of only a small amount of insulin after the intake of LCMs leads to rapid decreases of serum postprandial ketone body levels.

Postprandial triglyceride levels have attracted much attention as a cardiovascular risk factor $[15,16]$, and LCDs are well known to improve serum triglyceride profiles compared to HCDs $[7,13,17]$. Small amounts of dietary fats
(15 g) slightly increase postprandial serum triglyceride levels, but never decrease them in normolipidemic adults [18]. Interestingly, the present study demonstrated that small amounts of fat $(12 \mathrm{~g})$ in HCMs slightly decreased these levels over 2 hours in the strict CARD group in contrast to causing a slight increase in the moderate group. Moreover, $\Delta$ triglyceride was strongly and positively correlated with background dietary \%carbohydrate, but not with an increase in postprandial plasma glucose and serum insulin, insulinogenic index or total insulin secretory capacity. Specifically, postprandial triglyceride levels decreased more in strict CARD subjects with lower \%carbohydrate levels, and such patients had higher baseline ketone body levels. Given that ketone bodies provide the
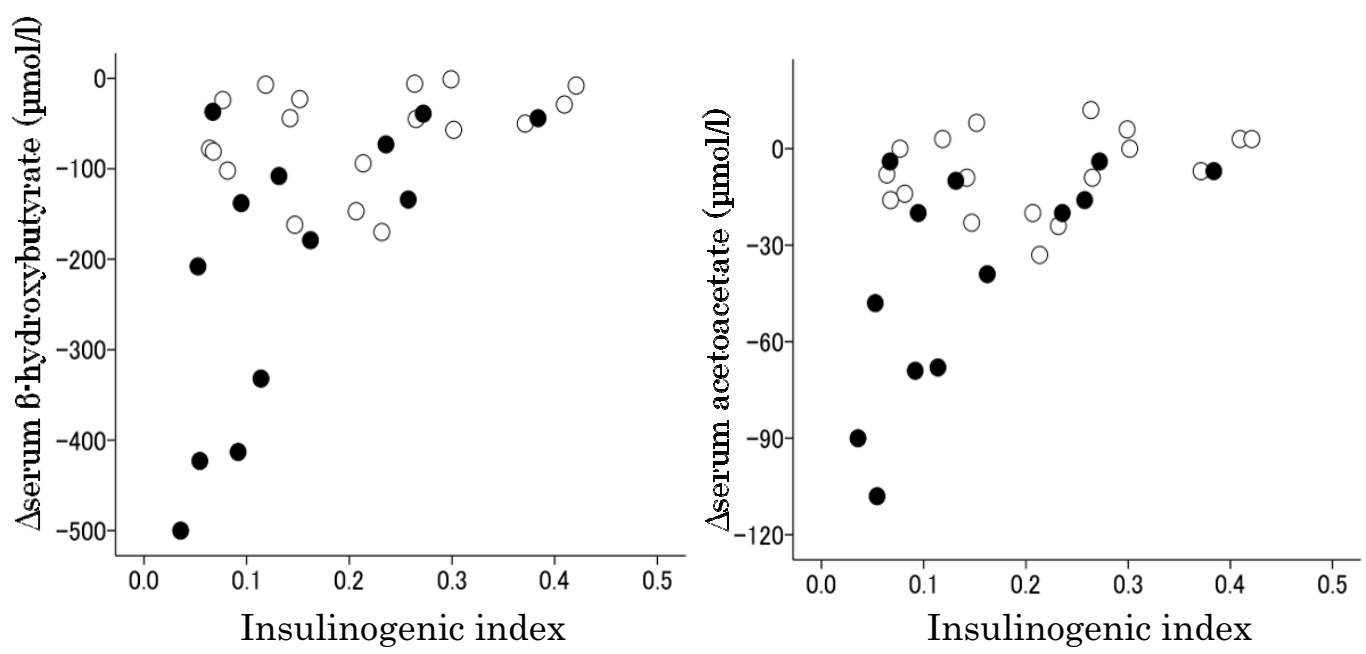

Figure 7

The relationship between ketone bodies (level at I 20 minutes - level at baseline) and the insulinogenic index after the intake of HCM. Closed and open circles indicate subjects in the strict and moderate CARD groups, respectively. The parameter $\Delta$ ketone bodies was significantly correlated with the insulinogenic index ( $\beta$-hydroxybutyrate: Spearman's $r=$ $0.503, P=0.004$; acetoacetate: Spearman's $r=0.509, P=0.003)$. 

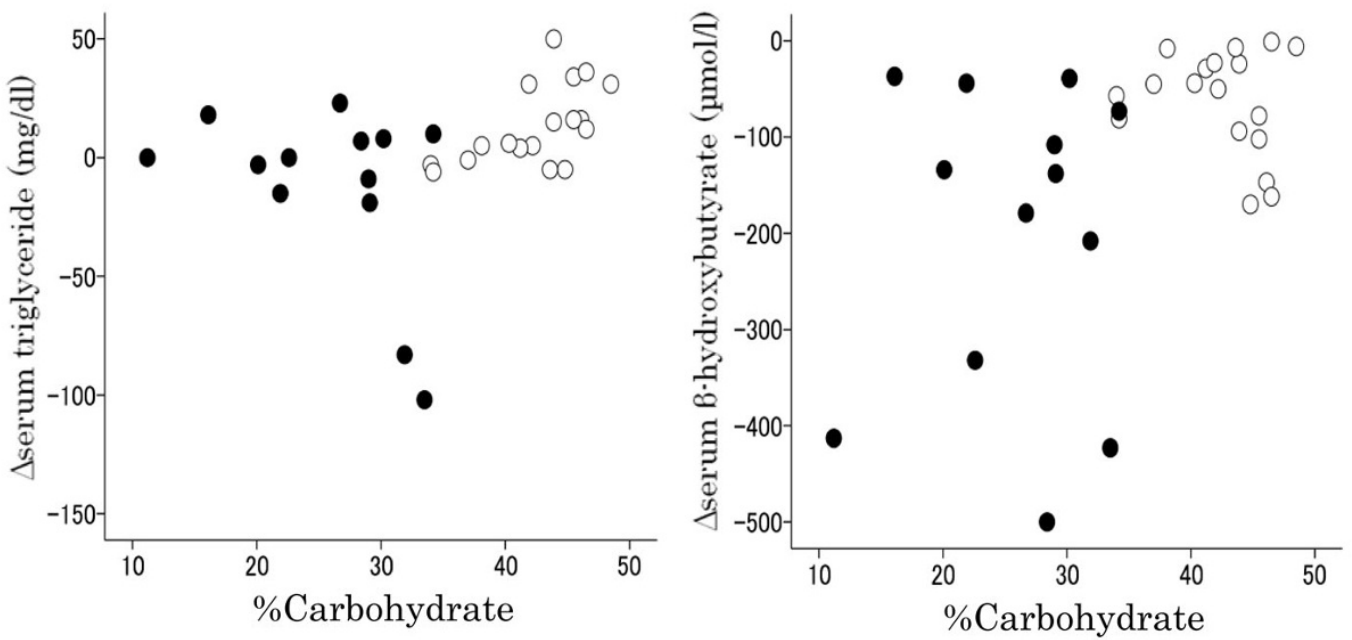

\section{Figure 8}

The relationship between triglyceride or -hydroxybutyrate (level at I 20 minutes - level at baseline) and background dietary \%carbohydrate after the intake of HCM. Closed and open circles indicate subjects in the strict and moderate CARD groups, respectively. Background dietary \%carbohydrate was strongly correlated with $\Delta$ triglyceride (Spearman's $r=0.484, P=0.006$ ) and was moderately correlated with $\Delta \beta$-hydroxybutyrate (Spearman's $r=0.380, P=0.035$ ). Excluding the two subjects with a greatest decrease of serum triglycerides did not materially alter the association between $\Delta$ triglyceride and dietary \%carbohydrate (Spearman's $r=0.487[P=0.007])$.

same metabolic effects as insulin and inhibit lipolysis $[7,19,20]$, serum ketone bodies may play a role in decreasing postprandial triglyceride levels. In contrast, large amounts of fat ( $42 \mathrm{~g}$ ) in LCMs increased triglyceride concentrations in both CARD groups. These results raise the possibility of a threshold in the dietary fat level under which postprandial triglyceride levels are not elevated [21].

In summary, when T2DM patients treated with CARD ingested HCMs, rapid metabolic change was induced within 2 hours; a rapid decrease in serum ketone bodies and FFA levels was found in conjunction with an increase in postprandial glucose and insulin levels. The decrease in ketone bodies was more remarkable in strict than in moderate CARD subjects. The parameter $\Delta$ ketone bodies was significantly correlated with the insulinogenic index, but not with total insulin secetory capacity. HCMs gradually decreased postprandial triglyceride levels in strict CARD subjects in contrast to causing a slight increase in moderate CARD subjects. The parameter $\Delta$ triglyceride was significantly correlated with dietary \%carbohydrate.

\section{Abbreviations}

CARD: carbohydrate-reduced diet; FFAs: free fatty acids; HbA1c: hemoglobin A1c; HCD: high-carbohydrate diet; HCM: high-carbohydrate meal; LCD: low-carbohydrate diet; LCM: low-carbohydrate meal; T2DM: type 2 diabetes mellitus.

\section{Competing interests}

The authors declare that they have no competing interests.

\section{Authors' contributions}

$\mathrm{HH}$ and TS designed the study and participated in data collection. $\mathrm{HH}, \mathrm{KW}$ and $\mathrm{HU}$ performed statistical analysis and interpretation. $\mathrm{HH}$ and $\mathrm{KW}$ wrote the manuscript. All authors read and approved the final manuscript.

\section{Acknowledgements}

The authors would like to thank the nurses at Haimoto Clinic for their assistance and excellent patient care, and Mrs. Aiko Haimoto for technical support.

\section{References}

I. Accurso A, Bernstein RK, Dahlqvist A, Draznin B, Feinman RD, Fine EJ, Gleed A, Jacobs DB, Larson G, Lustig RH, Manninen AH, McFarlane SI, Morrison K, Nielsen JV, Ravnskov U, Roth KS, Silvestre R, Sowers JR, Sundberg R, Volek JS, Westman EC, Wood RJ, Wortman J, Vernon MC: Dietary carbohydrate restriction in type 2 diabetes mellitus and metabolic syndrome: time for a critical appraisal. Nutr Metab (Lond) 2008, 5:9.

2. Westman EC, Yancy WS Jr, Mavropoulos JC, Marquart M, McDuffie JR: The effect of a low-carbohydrate, ketogenic diet versus a low-glycemic index diet on glycemic control in type 2 diabetes mellitus. Nutr Metab (Lond) 2008, 5:36.

3. Haimoto $H$, Iwata $M$, Wakai $K$, Umegaki $H$ : Long-term effects of a diet loosely restricting carbohydrates on HbAIc levels, BMI and tapering of sulfonylureas in type 2 diabetes: a 2-year follow-up study. Diabetes Res Clin Pract 2008, 79:350-356.

4. Haimoto H, Sasakabe T, Wakai K, Umegaki H: Effects of a low-carbohydrate diet on glycemic control in outpatients with severe type 2 diabetes. Nutr Metab (Lond) 2009, 6:21.

5. Daly ME, Paisey R, Millward BA, Eccles C, Williams K, Hammersley S, MacLeod KM, Gale TJ: Short-term effects of severe dietary car- 
bohydrate-restriction advice in Type 2 diabetes--a randomized controlled trial. Diabet Med 2006, 23:15-20.

6. Westman EC, Feinman RD, Mavropoulos JC, Vernon MC, Volek JS, Wortman JA, Yancy WS, Phinney SD: Low-carbohydrate nutrition and metabolism. Am J Clin Nutr 2007, 86:276-284.

7. Volek JS, Phinney SD, Forsythe CE, Quann EE, Wood RJ, Puglisi MJ, Kraemer W], Bibus DM, Fernandez ML, Feinman RD: Carbohydrate restriction has a more favorable impact on the metabolic syndrome than a low fat diet. Lipids 2009, 44:297-309.

8. Johnston CS, Tjonn SL, Swan PD, White A, Hutchins H, Sears B: Ketogenic low-carbohydrate diets have no metabolic advantage over nonketogenic low-carbohydrate diets. Am / Clin Nutr 2006, 83: $1055-106 \mid$.

9. Japan Diabetes Society: Treatment Guide for Diabetes. Bunkodo 2007.

10. Noakes M, Foster PR, Keogh JB, James AP, Mamo JC, Clifton PM: Comparison of isocaloric very low carbohydrate/high saturated fat and high carbohydrate/low saturated fat diets on body composition and cardiovascular risk. Nutr Metab (Lond) 2006, 3:7.

11. Dyson PA, Beatty S, Matthews DR: A low-carbohydrate diet is more effective in reducing body weight than healthy eating in both diabetic and non-diabetic subjects. Diabet Med 2007, 24: |430-| 435 .

12. Cahill GF Jr: Fuel metabolism in starvation. Annu Rev Nutr 2006, 26: I-22.

13. Volek JS, Fernandez ML, Feinman RD, Phinney SD: Dietary carbohydrate restriction induces a unique metabolic state positively affecting atherogenic dyslipidemia, fatty acid partitioning, and metabolic syndrome. Prog Lipid Res 2008, 47:307-318.

14. Aoki TT, Muller WA, Brennan MF, Cahill GF Jr: Metabolic effects of glucose in brief and prolonged fasted man. Am J Clin Nutr I975, 28:507-5। I.

15. Eberly LE, Stamler J, Neaton JD: Relation of triglyceride levels, fasting and nonfasting, to fatal and nonfatal coronary heart disease. Arch Intern Med 2003, 163:1077-1083.

16. O'Keefe JH, Bell DS: Postprandial hyperglycemia/hyperlipidemia (postprandial dysmetabolism) is a cardiovascular risk factor. Am J Cardiol 2007, 100:899-904.

17. Katan MB: Alternatives to low-fat diets. Am J Clin Nutr 2006, 83:989-990.

18. Dubois C, Beaumier G, Juhel C, Armand M, Portugal H, Pauli AM, Borel P, Latge C, Lairon D: Effects of graded amounts (0-50 g) of dietary fat on postprandial lipemia and lipoproteins in normolipidemic adults. Am J Clin Nutr 1998, 67:3 I-38.

19. Veech RL: The therapeutic implications of ketone bodies: the effects of ketone bodies in pathological conditions: ketosis, ketogenic diet, redox states, insulin resistance, and mitochondrial metabolism. Prostaglandins Leukot Essent Fatty Acids 2004, 70:309-319.

20. Taggart AK, Kero J, Gan X, Cai TQ, Cheng K, Ippolito M, Ren N, Kaplan R, Wu K, Wu TJ, Jin L, Liaw C, Chen R, Richman J, Connolly D, Offermanns S, Wright SD, Waters MG: (D)-beta-Hydroxybutyrate inhibits adipocyte lipolysis via the nicotinic acid receptor PUMA-G. J Biol Chem 2005, 280:26649-26652.

21. Kolovou GD, Anagnostopoulou KK, Daskalopoulou SS, Mikhailidis DP, Cokkinos DV: Clinical relevance of postprandial lipaemia. Curr Med Chem 2005, I 2: 193I-1945.
Publish with Biomed Central and every scientist can read your work free of charge

"BioMed Central will be the most significant development for disseminating the results of biomedical research in our lifetime. "

Sir Paul Nurse, Cancer Research UK

Your research papers will be:

- available free of charge to the entire biomedical community

- peer reviewed and published immediately upon acceptance

- cited in PubMed and archived on PubMed Central

- yours - you keep the copyright

Submit your manuscript here:

http://www.biomedcentral.com/info/publishing_adv.asp
BioMedcentral 